\title{
Ephrin-B3 is the midline barrier that prevents corticospinal tract axons from recrossing, allowing for unilateral motor control
}

\author{
Klas Kullander, ${ }^{1}$ Susan D. Croll, ${ }^{2}$ Manuel Zimmer, ${ }^{1}$ Li Pan, ${ }^{2}$ Joyce McClain, ${ }^{2}$ Virginia Hughes, ${ }^{2}$ \\ Stephanie Zabski, ${ }^{2}$ Thomas M. DeChiara, ${ }^{2}$ Rüdiger Klein, ${ }^{1}$ George D. Yancopoulos, ${ }^{2}$ and \\ Nicholas W. Gale ${ }^{2,3}$ \\ ${ }^{1}$ European Molecular Biology Laboratory, D-69117 Heidelberg, Germany; ${ }^{2}$ Regeneron Pharmaceuticals, Inc., Tarrytown, New \\ York 10591-6707, USA
}

\begin{abstract}
Growing axons follow highly stereotypical pathways, guided by a variety of attractive and repulsive cues, before establishing specific connections with distant targets. A particularly well-known example that illustrates the complexity of axonal migration pathways involves the axonal projections of motor neurons located in the motor cortex. These projections take a complex route during which they first cross the midline, then form the corticospinal tract, and ultimately connect with motor neurons in the contralateral side of the spinal cord. These obligatory contralateral connections account for why one side of the brain controls movement on the opposing side of the body. The netrins and slits provide well-known midline signals that regulate axonal crossings at the midline. Herein we report that a member of the ephrin family, ephrin-B3, also plays a key role at the midline to regulate axonal crossing. In particular, we show that ephrin-B3 acts as the midline barrier that prevents corticospinal tract projections from recrossing when they enter the spinal gray matter. We report that in ephrin-B $3^{-/-}$mice, corticospinal tract projections freely recross in the spinal gray matter, such that the motor cortex on one side of the brain now provides bilateral input to the spinal cord. This neuroanatomical abnormality in ephrin-B3 ${ }^{-/-}$mice correlates with loss of unilateral motor control, yielding mice that simultaneously move their right and left limbs and thus have a peculiar hopping gait quite unlike the alternate step gait displayed by normal mice. The corticospinal and walking defects in ephrin-B3 $3^{-/-}$ mice resemble those recently reported for mice lacking the EphA4 receptor, which binds ephrin-B3 as well as other ephrins, suggesting that the binding of EphA4-bearing axonal processes to ephrin-B3 at the midline provides the repulsive signal that prevents corticospinal tract projections from recrossing the midline in the developing spinal cord.
\end{abstract}

[Key Words: Eph; ephrin; receptor tyrosine kinase; corticospinal tract; axon guidance; floor plate]

Received November 22, 2000; revised version accepted February 13, 2001.

During development of the nervous system, axons travel through highly stereotypical pathways before establishing specific connections with distant neurons. A particularly well-known example that illustrates the complexity of axonal migration pathways involves the upper motor neurons of the motor cortex, which control voluntary movement by ultimately connecting with interneurons and lower motor neurons in the contralateral side of the spinal cord (Paxinos 1985). Axons from each side of the

${ }^{3}$ Corresponding author.

E-MAIL nicholas.gale@regeneron.com; FAX (914) 347-5045.

Article and publication are at www.genesdev.org/cgi/doi/10.1101/ gad.868901. motor cortex separately converge ipsilaterally as they pass through the internal capsule, and remain ipsilateral as they proceed to the caudal medulla. At this location, most of the axons cross or decussate the midline to the contralateral side and simultaneously shift from the ventral to dorsal aspect of the medulla. The axons continue contralaterally and dorsally, forming the corticospinal tract, which travels within the dorsal funiculus of the spinal cord. Axons from the corticospinal tract enter the dorsal aspect of the spinal gray matter and make connections with spinal motor neurons and interneurons. Remarkably, all these connections remain confined to the portion of the spinal cord, which is contralateral to the motor neurons from which the axons derive. These 
obligatory contralateral connections account for why one side of the brain controls movement on the opposing side of the body, and explains why patients who suffer from a stroke on one side of their brain show weakness and paralysis on the other side of their body.

A variety of attractive and repulsive cues apparently help guide axonal processes along their complex migration pathways. Several of these cues play key roles in the midline of multiple neural structures, because many axons must make key decisions as to whether to cross or not cross to the other side. Examples of cues known to act at the midline include the Netrins and the Slits, which have been implicated in midline decisions for several neuronal populations (Tessier-Lavigne and Goodman 1996; Kidd et al. 1998; Brose et al. 1999; Erskine et al. 2000; Piper et al. 2000). The ephrin ligands together with their Eph receptors provide for a large number of additional guidance cues, with eight known ephrin ligands and 14 known Eph receptors, which play important roles in axonal guidance (Gale and Yancopoulos 1997; Flanagan and Vanderhaeghen 1998). Such roles have been most extensively explored during the process by which retinal axons topographically project to the optic tectum (Flanagan and Vanderhaeghen 1998). Evidence in the retinotectal system and others suggests that ephrins guide axons by repelling them from inappropriate territories in a concentration dependent manner. Ephrins are interesting guidance molecules in that they cannot function at a distance, but only through direct contact between cells and/or their processes. This is the case because ephrins are membrane-attached molecules, and this attachment appears to be a requisite for their ability to activate their cognate receptors (Davis et al. 1994; Gale and Yancopoulos 1997).

Although ephrin ligands have been implicated in repulsive sorting of axons in the optic chiasm (Nakagawa et al. 2000; Marcus et al. 2000), no ephrin has yet been shown to be unequivocally involved in midline crossing decisions in the mouse. However, during embryonic development, ephrin-B3 displays striking expression in midline structures, suggesting that it may play a key role at the midline (Gale et al. 1996a; Imondi et al. 2000). To explore this possibility, we generated animals lacking ephrin-B3. These mutant mice display a remarkable neurologic phenotype marked by the absence of unilateral motor control. Most notably, these animals hop because they have lost the ability to individually move their right and left limbs, instead moving their right and left limbs simultaneously. The neurologic phenotype in these mutant mice apparently results from a midline abnormality involving the aforementioned corticospinal tract. Upon entering the spinal gray matter, these axons no longer remain confined to the side which they enter, and instead aberrantly cross the midline to make bilateral connections throughout the cord, apparently resulting in the lack of unilateral motor control. Consistent with the notion that ephrin-B3 acts as the critical midline barrier that normally prevents such abnormal crossing within the dorsal gray matter, we report that ephrin-B3 is normally expressed at the midline of the spinal cord, at the time when these axons are making their connections. Similar defects recently described in mice lacking EphA4 (Dottori et al. 1998; Kullander et al. 2001) indicate that EphA4 is the receptor on corticospinal tract axons that recognizes ephrin-B3 as a midline barrier in the spinal cord.

\section{Results}

Generation of ephrin-B3 knockout mice

To evaluate the potential functions of ephrin-B3 in the mouse nervous system, we used homologous recombination in ES cells to create a null allele for the endogenous mouse ephrin-B3 gene by replacing the coding region of the first exon of this gene with the LacZ and Neomycin genes (Fig. 1A). Correct targeting in ES cells was confirmed by Southern blotting, and these ES cells were then used to generate mice heterozygous (ephrin$\mathrm{B}^{+/-}$) or homozygous (ephrin-B3 ${ }^{-/-}$) for the null ephrinB3 allele (Fig. 1B). Northern blot analysis from brain tissue of these mice revealed that ephrin-B $3^{+/-}$mice had decreased levels of the ephrin-B3 transcript, whereas ephrin-B3 ${ }^{-/-}$mice completely lacked ephrin-B3 expression (Fig. 1C); unfortunately, the LacZ gene product, which was intended to act as a surrogate marker for ephrin-B3 expression, was not produced in these mice.

\section{Ephrin-B3 knockout mice display a lack of unilateral motor control}

Ephrin-B3 ${ }^{+/-}$mice showed no overt phenotype, and were not further characterized. Although ephrin-B3 ${ }^{-/-}$mice were born at the expected Mendelian frequencies, gained weight normally, were fertile, and otherwise appeared healthy and morphologically indistinguishable from control littermates, they displayed obvious neurologic abnormalities. Neurologically, ephrin-B3 ${ }^{-/}$mice showed obviously abnormal locomotion as soon as normal walking could be observed (post-natal day 8-10). Most notably, ephrin-B3 ${ }^{-/}$mice appeared unable to move their limbs independently and instead moved them synchronously in a hopping fashion (Fig. 2). In addition, they appeared reluctant to explore their cages, listed from side to side particularly when stressed, and appeared as if they might fall to one side or the other although they did not fall. To further evaluate these neurological and locomotive defects, several behavioral analyses were undertaken.

Gait analysis revealed substantial abnormalities in the ephrin-B3 ${ }^{-/-}$mice. Visual inspection of the footprints for wild-type mice revealed a normal, alternating step pattern, with long, even strides and the placement of each hind paw where the forepaw had been (Fig. 2, left panels). In marked contrast, the ephrin-B3 ${ }^{-/-}$mice showed no real alternation of their steps, but instead kept their front paws side by side and their hind paws side by side, and moved by first hopping on their two front paws and then hopping on their two hind paws (Fig. 2, right panels). This loss of alternation was accompanied by significantly decreased stride length as well as significantly 


\section{A Targeting Construct}

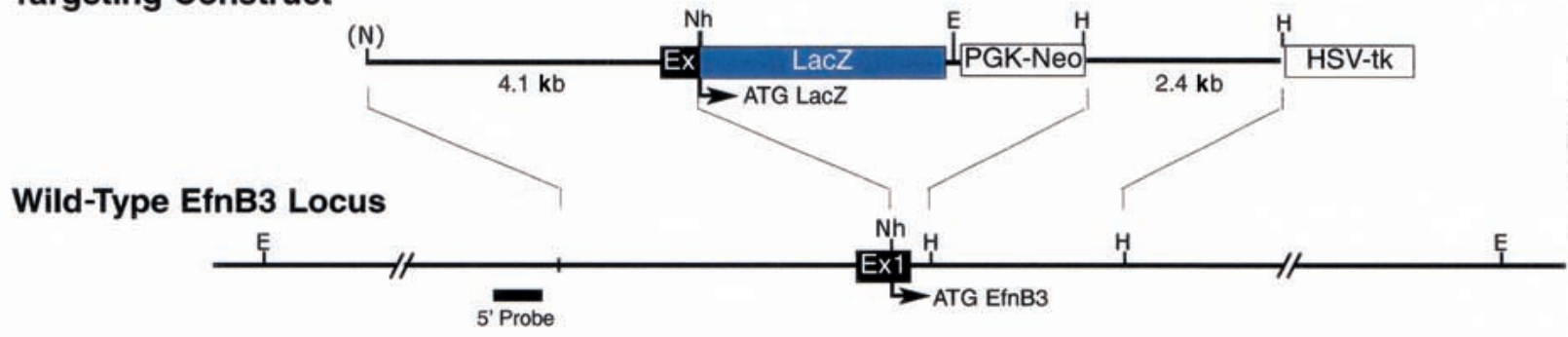

Targeted EfnB3 Locus

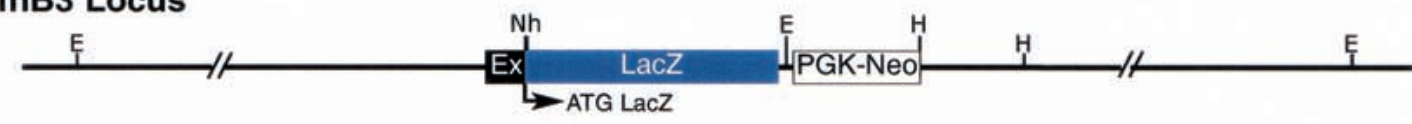

EcoR1 Restriction Fragments

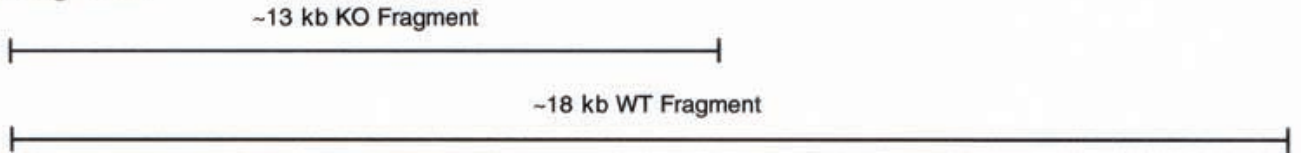

B

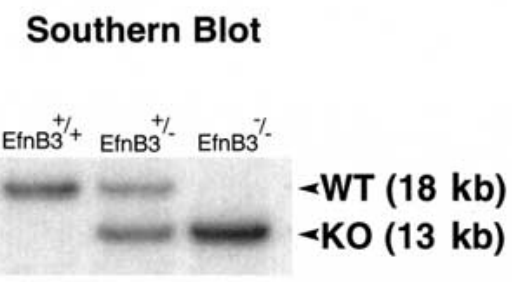

C

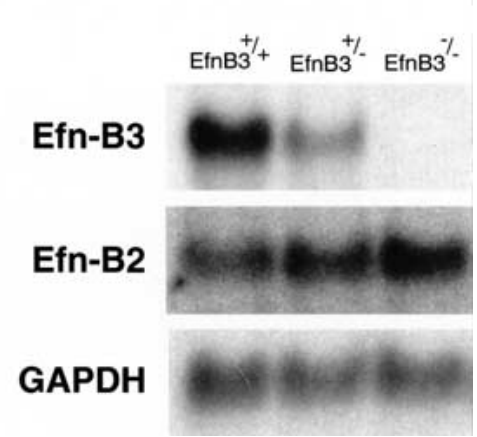

Figure 1. Ephrin-B3 gene targeting strategy. (A) A targeting construct was designed to abolish expression of ephrin-B3 by replacing the coding region of the first coding exon (black box, Ex1) of the ephrin-B3 gene with the coding region of the Escherichia coli LacZ gene (see Materials and Methods); neomycin (PGK-Neo), and thymidine kinase (HSV-tk) gene cassettes were incorporated to allow for selection of appropriate gene targeting events. The correctly targeted ephrin-B3 gene locus is depicted, showing the predicted restriction fragments diagnostic of the normal and targeted alleles after restriction of DNA with EcoRI, and probing the resultant restriction fragments by Southern

blotting using probes derived from the $5^{\prime}$ region of the gene outside of the $5^{\prime}$ region of homology used in the targeting constuct. (E, EcoRI; Nh, NheI; H, HindIII; N, NotI) (B) Appropriate gene targeting was confirmed in ES cells (not shown) and in $\mathrm{F}_{2}$ progeny resulting from the mating of $F_{1}$ male and female heterozygous mice. Examples of the resultant genotypes are shown. $(C)$ Gene targeting of the ephrin-B3 locus results in the absence of expression of ephrin-B3 mRNA, as revealed by northern blots from a variety of tissues, including adult brain, shown here. Expression of ephrin-B2 and GAPDH were examined on the same blot to confirm equal loading of lanes.

decreased interstep distance (the distance measured between the placement of the left and right paws) in the ephrin-B3 ${ }^{-I-}$ mice (Table 1). One interesting observation was that many of the steps taken by the ephrin-B3 ${ }^{-/-}$ mice (observed frequently in three of four animals) had intervening left forepaw placements, that is, there were often two front left forepaw placements for each single placement of the three other paws. It is unlikely that cerebellar dysfunction accounts for this walking abnormality, because cerebellar dysfunction is normally accompanied by a compensatory widening of stance during movement (as seen in cerebellar mutants, e.g., Guastavino et al. 1990), and the ephrin-B3-/- mice had normal stance width (Table 1). Furthermore, no cerebellar abnormalities were observed histologically (data not shown).
A sticker test was performed on these mice to evaluate fine motor coordination. There were no significant differences between wild-type and the ephrin-B3 ${ }^{-/-}$mice in their latency to remove a sticker from their snouts (Table 1), suggesting no substantial impairment in fine motor functioning in these animals.

Balance and sensorimotor coordination were evaluated using the Rotorod Test. Although the ephrin-B3 ${ }^{-/-}$mice showed a listing phenotype suggesting potential problems in balance (see above), there were no significant differences between wild-type and the ephrin-B3 $3^{-/-}$mice in their ability to walk on the rotorod within the rotation speeds tested (Table 1). This finding suggests that the ephrin-B3 ${ }^{-/}$mice were able to balance adequately and to coordinate their limbs sufficiently well to rise to the challenges provided by the rotorod. 

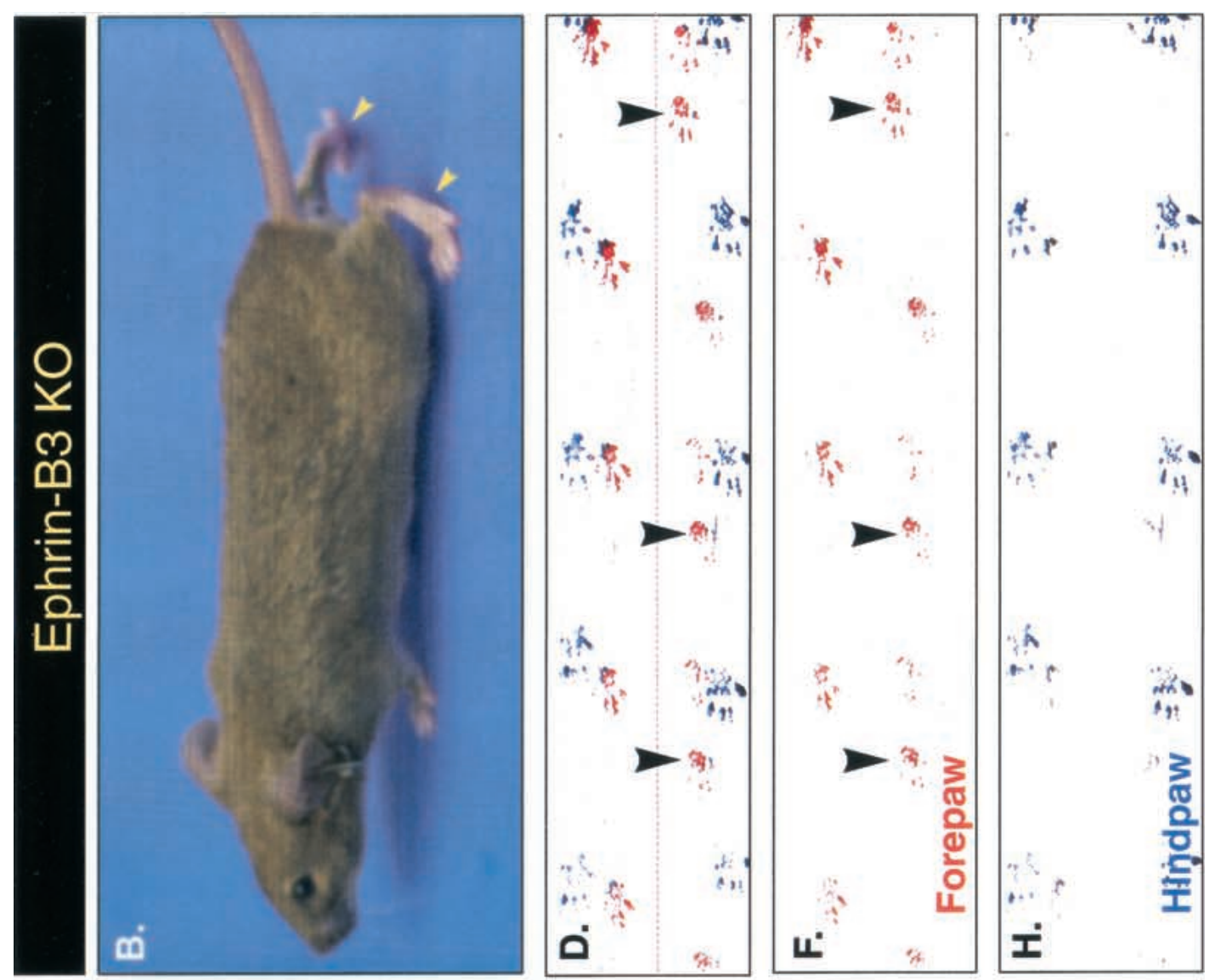

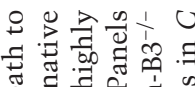

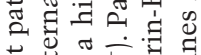

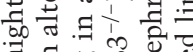

तี

क $3 . \exists . \underbrace{3}$

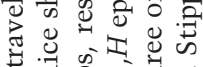

ᄋ

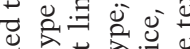

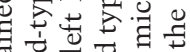

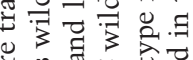

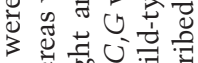

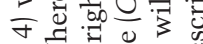

II

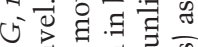

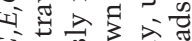

U.

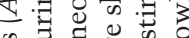

एँ

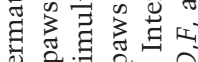

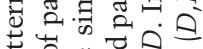

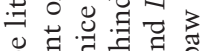

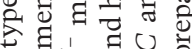

可

उत्व

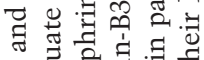

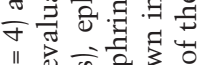

॥ के के है

요단
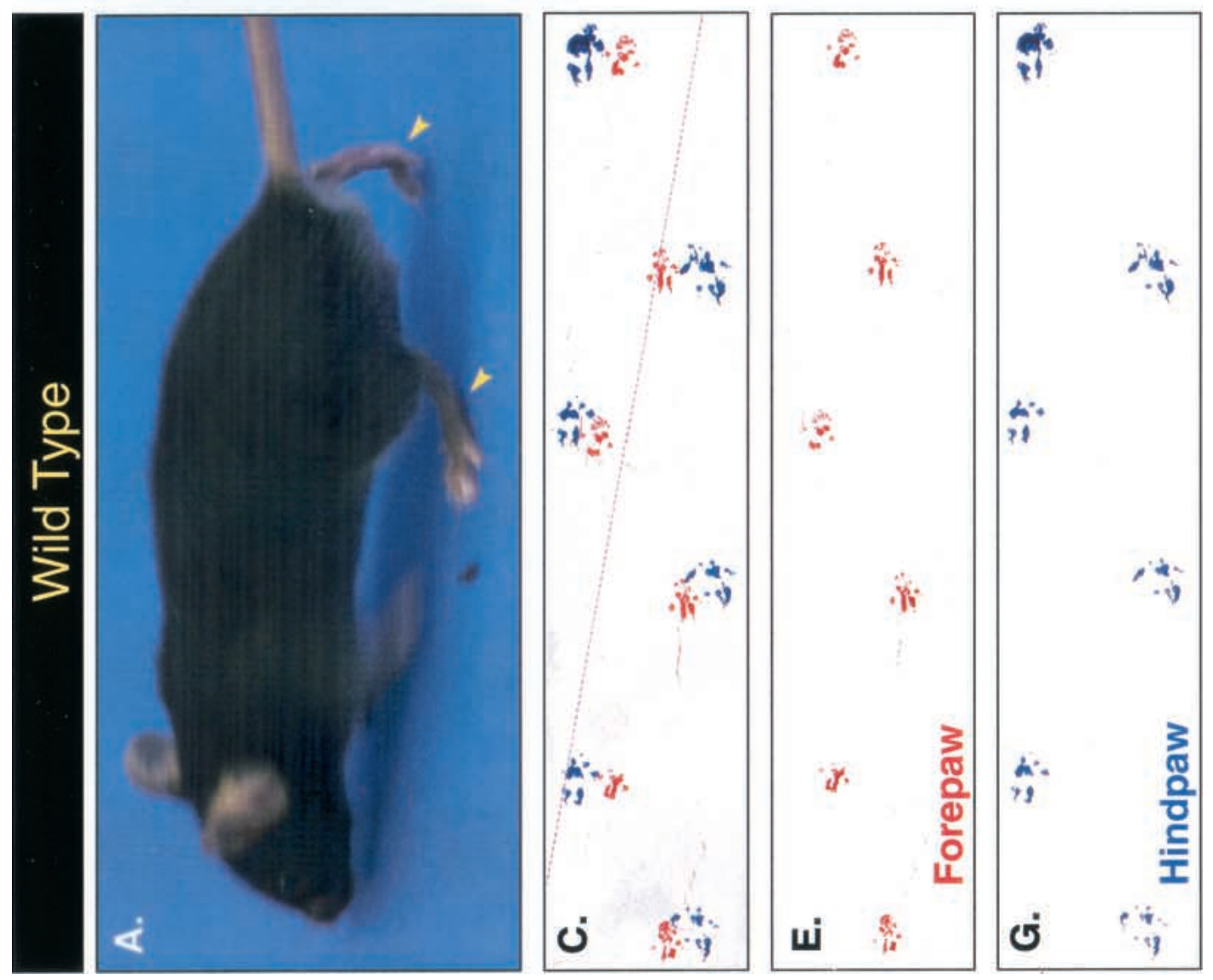

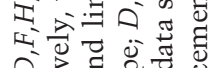

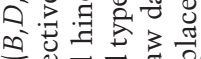

记

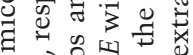

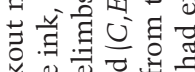

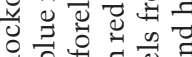

켜ㄴㅕㅖ

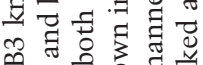

过苛究

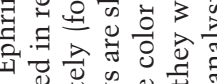

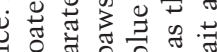

记

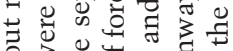

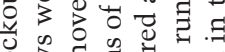

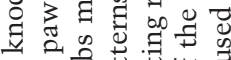

๗

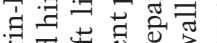

记

के क्ष

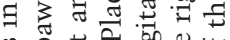

की

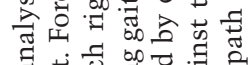

菏.

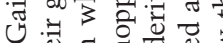

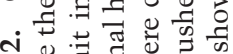

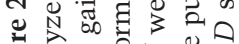

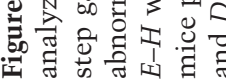


Table 1. Neurologic performance of ephrin-B3 knockout mice

\begin{tabular}{|c|c|c|c|}
\hline Parameter & $\begin{array}{l}\text { Wild type } \\
\quad(n=4)\end{array}$ & $\begin{array}{c}\text { Ephrin-B3 KO } \\
\quad(n=4)\end{array}$ & $p$ Value \\
\hline Left front stride length (mm) & $79.0 \pm 1.6$ & $35.5 \pm 5.3$ & $\mathrm{p}<0.0002^{*}$ \\
\hline Right front stride length (mm) & $76.5 \pm 1.8$ & $44.8 \pm 1.7$ & $\mathrm{p}<0.0001^{\star}$ \\
\hline Left rear stride length $(\mathrm{mm})$ & $75.0 \pm 2.3$ & $55.0 \pm 3.8$ & $\mathrm{p}<0.004^{\star}$ \\
\hline Right rear stride length (mm) & $77.0 \pm 3.0$ & $56.0 \pm 6.0$ & $\mathrm{p}<0.02^{\star}$ \\
\hline Rear inter-step distance $(\mathrm{mm})$ & $39.8 \pm 5.8$ & $5.8 \pm 1.8$ & $\mathrm{p}<0.0001^{\star}$ \\
\hline Front inter-step distance (mm) & $38.8 \pm 0.6$ & $6.8 \pm 2.3$ & $\mathrm{p}<0.0001^{\star}$ \\
\hline Rear base width (mm) & $27.2 \pm 2.1$ & $29.8 \pm 1.2$ & $\mathrm{p}>0.35$ \\
\hline Front base width (mm) & $15.0 \pm 1.5$ & $18.8 \pm 1.2$ & $\mathrm{p}>0.09$ \\
\hline Sticker test (latency, sec) & $5.5 \pm 1.4$ & $7.2 \pm 2.2$ & $\mathrm{p}>0.53$ \\
\hline Rotorod (latency, sec) & $120.0 \pm 0.0$ & $116.2 \pm 3.8$ & $\mathrm{p}>0.36$ \\
\hline
\end{tabular}

Data are expressed as mean \pm SEM.

${ }^{\star}$ Statistically significant by Student's independent groups t-test, $\mathrm{p}<0.05$.

Ephrin-B3-/- mice exhibit abnormal corticospinal tracts, with axonal recrossing in the spinal cord

The inability of the ephrin-B3 ${ }^{-/-}$mice to unilaterally control their limb movements suggested the possibility that these mice might have abnormalities in their corticospinal tracts. Histological analysis of lumbar spinal cord cross sections revealed abnormal morphology of the dorsal funiculus in the ephrin-B3 ${ }^{-/-}$mice, which appeared more shallow and widened in comparison to the dorsal funiculus of wild-type mice (Fig. 3C,D). To visualize the path taken by corticospinal tract axons, we performed anterograde axon tracing experiments by injecting tracer into one side of the motor cortex and observing the terminal projections in the spinal cord $(n=6)$. All mice were age matched (6-8 wk old) and examined for correct unilateral labeling of the motor cortex. As also seen in the wild-type mice, dense labeling of axons was noted in the ventromedial portion of the contralateral dorsal funiculus in the ephrin- $3^{-/-}$mice (Fig. 3E-H), indicating that even in the ephrin- $3^{-/-}$mice the corticospinal tract axons had correctly crossed to the opposing side and had correctly localized within the contralateral dorsal funiculus. As noted above, these tracings did confirm the shallower and wider appearance of the corticospinal tract in the ephrin-B3 ${ }^{-/-}$mice. More strikingly, however, the tracing analysis revealed a dramatic difference in the path of ephrin-B3 ${ }^{-/-}$corticospinal axons on entering the spinal dorsal gray matter. In the wildtype mice, projections into the gray matter remained confined to the contralateral gray matter, never crossing the midline, as shown in cervical sections (Fig. 3E) and lumbar sections (Fig. 3G). In marked contrast, the corticospinal tract projections of ephrin-B3 ${ }^{-/-}$mice clearly crossed over the midline into the ipsilateral gray matter (Fig. 3F,H). Thus, axons arising in the motor cortex correctly cross into the contralateral corticospinal tract in the ephrin-B3 ${ }^{-/-}$mice, but then aberrantly project into both the contralateral and ipsilateral gray matter of the spinal cord. The aberrant recrossing of fibers was observed throughout the rostrocaudal extent of the spinal cord.
Ephrin-B3 is expressed at the midline as a barrier to prevent corticospinal tract recrossing

The above abnormalities in the corticospinal projections are quite similar to those reported for mice lacking a receptor, EphA4, which binds ephrin-B3 with high affinity (Gale et al. 1996a; Dottori et al. 1998; Kullander et al. 2001). Because it has been shown that corticospinal tract axons express EphA4 receptor (Martone et al. 1997), the similar phenotype we observe in the ephrin-B3-/- mice might be because of a role that ephrin-B3 normally plays in preventing EphA4-expressing corticospinal tract axons from crossing the midline once they have projected into the spinal gray matter. If this were the case, one might expect ephrin-B3 to be localized at the midline when these projections occur, thus acting as a repulsive midline barrier for EphA4-expressing axons. Previous analyses reveal that ephrin-B3 is prominently expressed at the midline of the developing spinal cord at early embryonic stages, before the time of corticospinal tract formation (Gale et al. 1996a; Imondi et al. 2000). We now report that ephrin-B3 continues to be prominently expressed in midline of the developing spinal cord at later stages (E18.5), at a time when corticospinal tract projections are entering into the spinal gray matter (Fig. 4). Thus, ephrin-B3 expression patterns in the developing spinal cord, together with the abnormal crossing patterns seen in the ephrin-B3 ${ }^{-/-}$mice, strongly argue that ephrin-B3 acts as the midline barrier that prevents corticospinal tract projections from recrossing back to the ipsilateral side during postnatal development.

If ephrin-B3 is a midline barrier, which prevents recrossing of corticospinal tract projections, how can corticospinal tract fibers initially cross the midline at the medullary decussation? The developing somatomotor cortex, in which the cell bodies of the corticospinal tract reside, express EphA4 before the corticospinal tract axons reach the medullary decussation (Kullander et al. 2001). We reasoned that if the corticospinal tract axons are responsive to ephrin-B3 expression throughout development, ephrin-B3 should not be expressed in a manner that would interfere with the medullary decussation. 
Kullander et al.
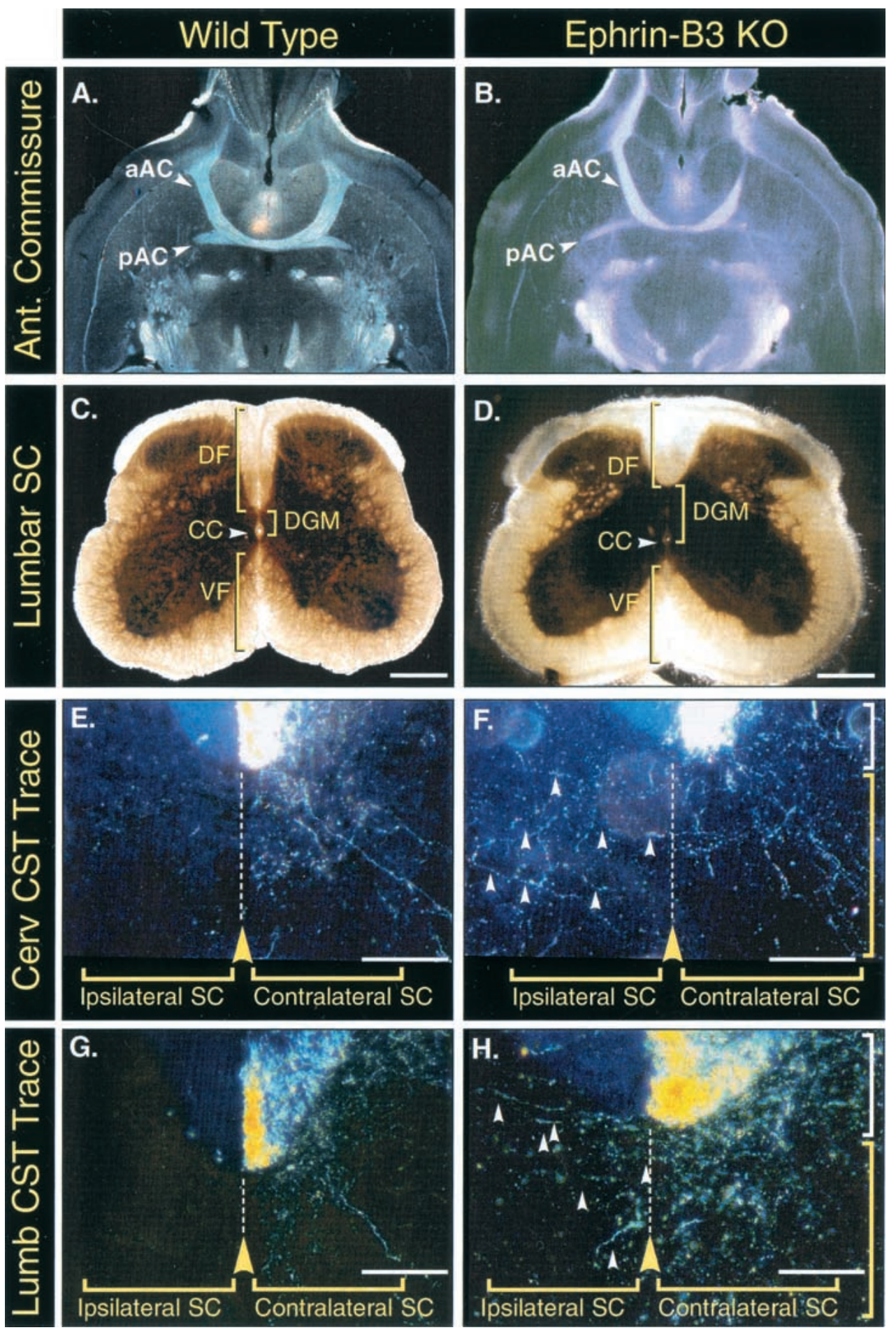

Figure 3. Normal morphology of the anterior commissure, but abnormal corticospinal tracts, in ephrin-B3 knockout mice. $(A, C, E, G)$ Wild-type mice. $(B, D, F, H)$ ephrin-B3 $3^{-/-}$mice. $(A, B)$ Horizontal brain sections from adult wild-type and ephrin-B3 knockout mice show that both the anterior and posterior components of the anterior commissure (aAC and pAC respectively) form normally. (C,D) Lumbar spinal cord sections reveal a morphological abnormality in the formation of the dorsal funiculus (DF). Compared to wild types, ephrin-B3 ${ }^{-/-}$animals show a more shallow and widened dorsal funiculus. In addition, the gray matter (DGM) dorsal to the central canal (CC) appears expanded compared to that seen in wild-type spinal cords. The ventral funiculus (VF) appears morphologically normal in ephrin-B ${ }^{-1-}$ mice. Scale bars $C$ and $D, 200 \mu \mathrm{m}$. $(E-H)$ Anterograde tracings of corticospinal tract $(\mathrm{CST})$ axons by injecting tracer into the motor cortex and sectioning at either cervical $(E, F)$ or lumbar $(G, H)$ levels reveal that these axons are appropriately positioned within the dorsal funiculus (white brackets) on the side contralateral to the tracer injections, but aberrantly cross the midline once they project into the spinal gray matter (yellow brackets) in the ephrin-B $3^{-/-}$mice at both cervical and lumbar levels $(F, H$, arrowheads). Note the shallower appearance of the dorsal funiculus in the sections from the mutant mice. Scale bars $E-H, 70 \mu \mathrm{m}$. 

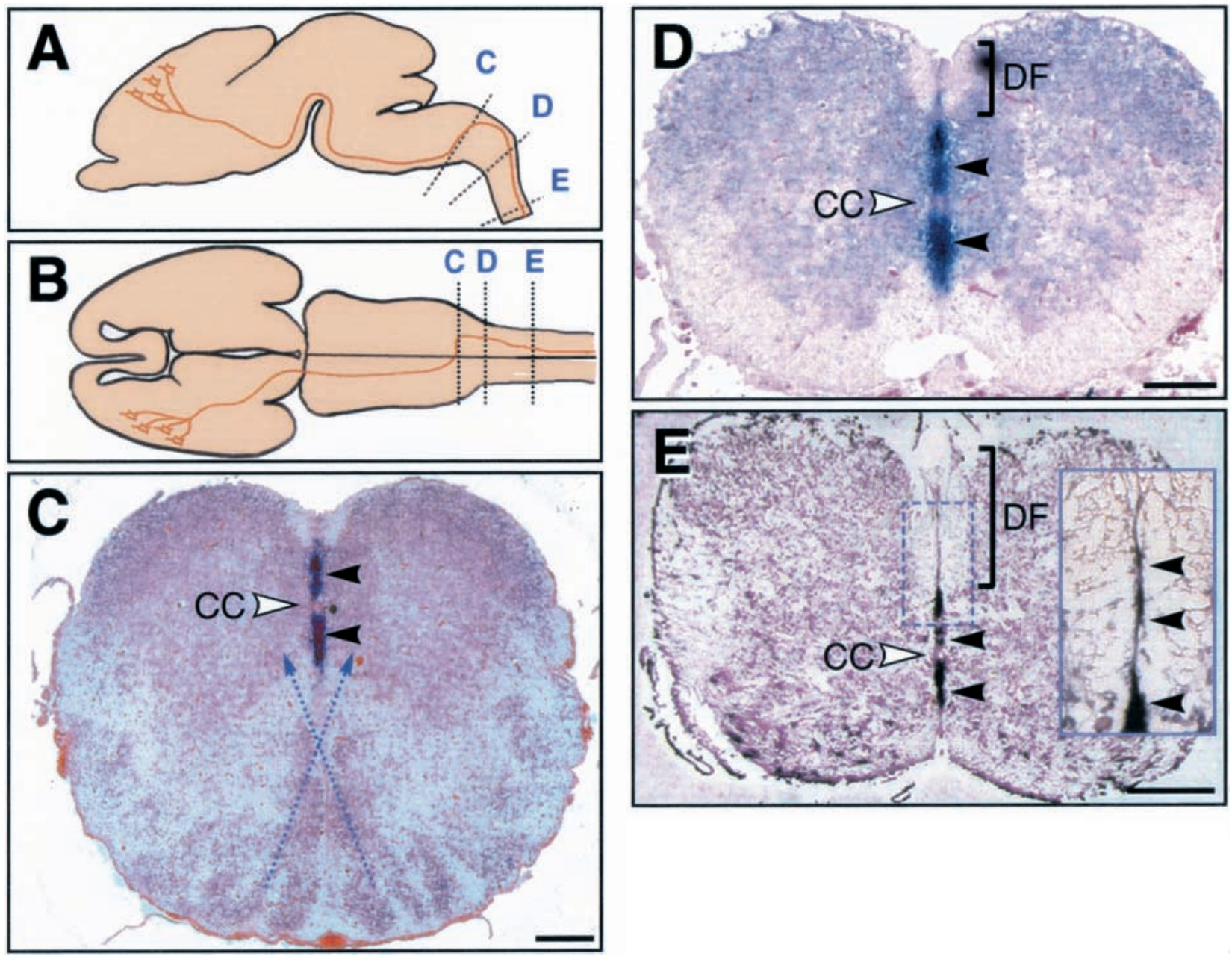

Figure 4. Expression analysis of ephrin-B3 in wild-type mouse spinal cord sections reveals that ephrin-B3 is expressed in the midline. $(A, B)$ Schematic lateral $(A)$ and dorsal $(B)$ views of E18.5 mouse brain indicating the location of the CST and the sections taken for panels $C-E$, with $C$ at the site of the medullary decussation and those at $D$ and $E$ representative of more caudal sections through the spinal cord. (C-E) DIG in situ hybridizations (blue staining, black arrowheads) on coronal sections of the E18.5 medullary decussation and spinal cord. In $C$ at the medullary decussation, which occurs ventrally (with stippled lines indicating approximate path of decussating fibers), ephrin-B3 is detected only in the dorsal portion of the midline and not in the ventral midline. In $D$ and $E$, sections of the cervical and thoracic spinal cord are shown in which the ephrin-B3 expression extends over the ventral part of the midline. A higher magnification view of the dorsal funiculus (stippled box and inset) also reveals expression of ephrin-B3 in the midline of the dorsal funiculus. CC, central canal; DF, dorsal funiculus. Scale bars, $200 \mu \mathrm{m}$.

Therefore, we performed in situ hybridizations along the rostro-caudal axis to determine the nature of ephrin-B3 expression at the point of decussation and caudal to this point (Fig. 4). Indeed, at E18.5 when pioneering axons of the corticospinal tract have reached the medullary decussation where they cross ventrally and then move dorsally to form the dorsal funiculus (Joosten and Bar 1999), ephrin-B3 expression is limited to the dorsal part of the midline in the medulla in a position consistent with it not interfering with the ventral crossing (Fig. 4C, arrowheads). Caudal to the decussation, the dorsal midline expression of ephrin-B3 then expands ventrally (Fig. 4D,E), in which it presumably acts to prevent recrossing of projections in the spinal gray matter. Ephrin-B3 expression is also detected as a thin stripe in the midline of the developing dorsal funiculus (Fig. 4E); although, we detect a few fibers that aberrantly cross the midline in the dorsal funiculus in ephrin-B3 mutant mice (data not shown), it seems that there are other more dominant cues that prevent defasciculation and aberrant recrossing within the dorsal funiculus of the mutant mice. From the above results we conclude that corticospinal tract axons expressing EphA4 initially cross the midline at the medullary decussation where no ephrin-B3 is expressed, that ephrin-B3 plays a minor role in preventing recrossing within the dorsal funiculus, but that subsequent recrossing following entry of corticospinal tract projections into the spinal gray matter is largely prevented by midline expression of ephrin-B3 throughout the rostro-caudal extent of the cord. 
Ephrin-B3 induces growth cone collapse of EphA4-positive cortical neurons in vitro

The above findings suggest a role for ephrin-B3 as a midline barrier for growing corticospinal tract axons. One prediction of this model would be that corticospinal tract axons should respond to ephrin-B3 signals in vitro, possibly by eliciting growth cone collapse activity on EphA4 expressing axons, as has been shown for other systems in which ephrins show barrier functions (e.g., Imondi et al. 2000). To test this possibility, we took advantage of the reported EphA4 expression in the embryonic cortical plate from which the corticospinal tract axons arise (Kullander et al 2001). Embryonic (E16.5) cortical cultures prepared from a novel EphA4 gene trap mouse, in which placental alkaline phosphatase expression is controlled by EphA4 regulatory elements (Leighton et al. 2001), confirmed that $\sim 80 \%$ of the neurons in these cultures express EphA4. E16.5 cortical cultures were plated and allowed to send out axons for two days after which they were treated with clustered control Fc protein, or with clustered ephrin-B3-Fc. After treatment, phalloidin staining of actin filaments was performed to reveal the morphology of the axons and their associated growth cones, and the cultures were scored for collapsed or uncollapsed growth cones (see Materials and Methods; Fig. 5A,B). In cultures treated with ephrin-B3 $(n=10)$, 581 growth cones were collapsed out of 934 counted $(62 \%)$, whereas in the Fc control treated cultures $(n=13)$ only 410 of 1268 (32\%) of the neurons had a collapsed growth cone. Untreated cultures were similar in the amount of uncollapsed growth cones observed in comparison to Fc treated cultures $(n=4)$, with 93 growth cones collapsed of 327 counted (28\%). The significant specific increase in growth cone collapse by ephrin-B3 in cortical cultures further supports the hypothesis that ephrin-B3 acts as a midline barrier for corticospinal tract axons.

\section{Discussion}

Extending existing evidence that ephrins provide important axon guidance cues during neuronal development, our findings show that ephrin-B3 plays a key role as a midline repulsive barrier that prevents corticospinal tract axons from recrossing once they enter the spinal gray matter. Our findings provide the first evidence that ephrins can play guidance roles within the spinal cord, and add ephrin-B3 to the short list of key signals, such as netrins and slits (Tessier-Lavigne and Goodman 1996; Kidd et al. 1998; Brose et al. 1999; Erskine et al. 2000; Piper et al. 2000), acting at the midline. Interestingly, none of these other signals appears to be involved in preventing corticospinal tract axons from recrossing, suggesting that ephrin-B3 plays a particularly important midline role for these axons.

The remarkable neurologic symptoms displayed by the ephrin-B3 ${ }^{-/-}$mice can apparently be accounted for by the aberrant recrossing of corticospinal tract axons in these mice. Because each side of the motor cortex no longer specifically controls the opposing side of the body in the ephrin-B3 ${ }^{-/}$mice, but instead provides bilateral input to both sides of the body, these mice cannot unilaterally control their body movements. This inability to dictate unilateral movement apparently accounts for the
Figure 5. Examples of scored neurons in phalloidin stained cortical cultures treated with preclustered Fc control or ephrin-B3Fc. Stippled boxes indicate enlarged regions of growth cones to better visualize morphology. (A) A neuron with an unaffected growth cone and normal dendrite morphology. (B) A collapsed growth cone with normal looking dendrites and cell body indicative of a general healthy state of the cultures. Note the lesser extent of spicules on the axon as compared to $A$.
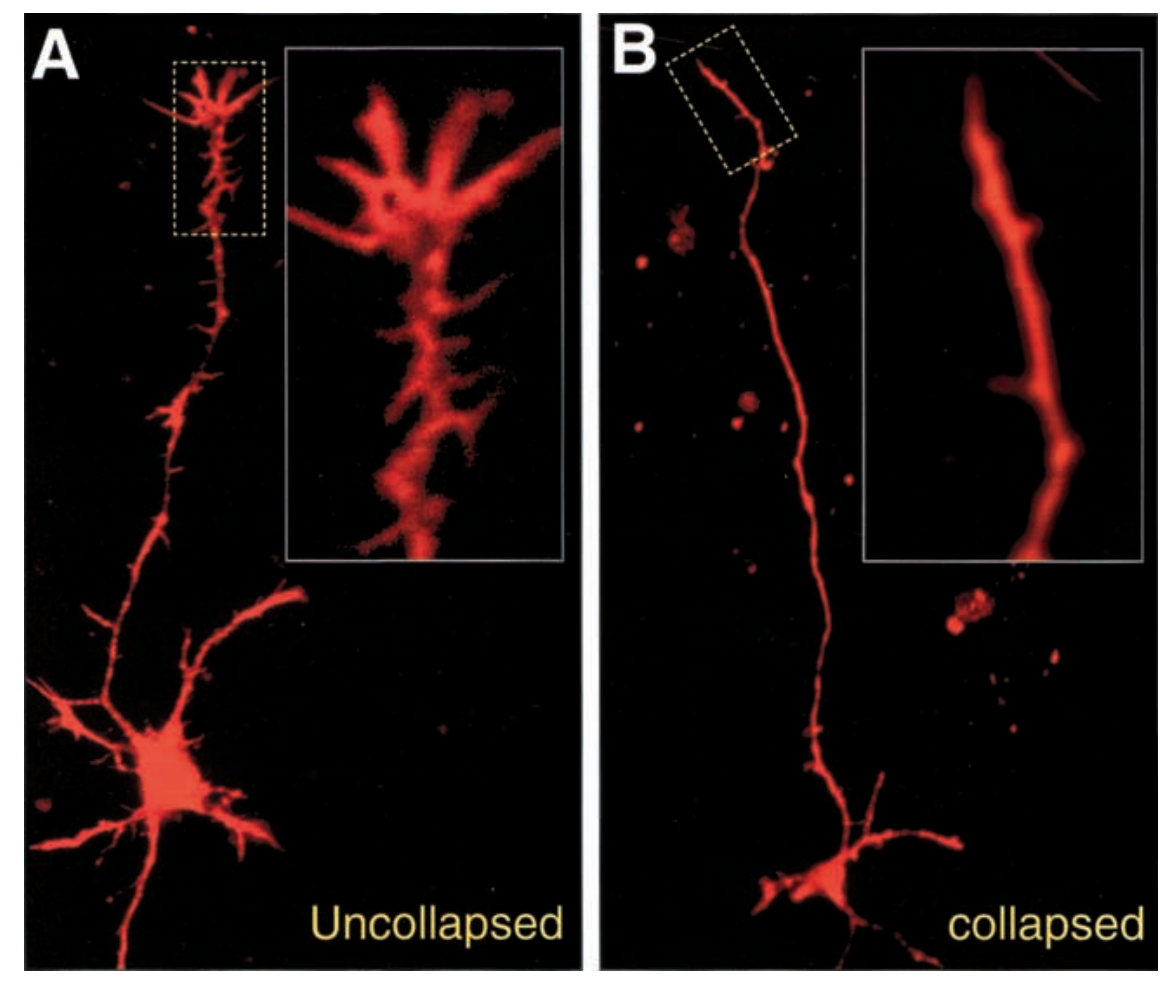
simultaneous movements of right and left paws in the ephrin-B3 ${ }^{-/-}$mice, resulting in the abnormal hopping gait as opposed to the conventional alternating paw gait characteristic of normal mice. An interesting prediction that can be made about the ephrin-B3 $3^{-/-}$mice is that they should respond quite differently to lesions to one side of the motor cortex; such lesions would not be expected to cause corresponding weakness on the contralateral side of the body, as seen in normal animals, because of the ability of the remaining side of the motor cortex to cause bilateral movement.

Although it is most parsimonious to attribute all of the gait abnormalities in the ephrin- $3^{-/-}$mice to the altered structure of their corticospinal tracts, other mechanisms cannot be ruled out. It should further be noted that it is very likely that the ephrin-B3 ${ }^{-/-}$mice have additional axonal guidance defects not described herein, perhaps involving the midline as well. This possibility is supported by the findings that ephrin-B3 is expressed at the midline at many different stages of embryonic development, including midline structures rostral to the decussation of the corticospinal tract axons. Regarding this latter point, it should also be noted that ephrin-B3 undergoes a fascinating shift in its midline expression patterns that seemingly allows for initial decussation of the corticospinal tract while preventing its subsequent recrossing. That is, at the decussation, which occurs in the ventral medulla, ephrin-B3 is only found at the dorsal midline, thus apparently not interfering with the initial ventral decussation. Caudal to this decussation, ephrin-B3 expression moves ventrally, perfectly positioned to prevent recrossing of corticospinal tract projections. It should also be noted that the rather normal appearance of the medullary decussation in the ephrin$\mathrm{B}^{-/-}$mice implies that signals other than ephrin-B3 control this complex midline crossing phenomenon.

The abnormal widening of the corticospinal tract and dorsal funiculus in the ephrin-B3 ${ }^{-/}$mice suggests that ephrin-B3 plays roles in organizing this part of the spinal cord before corticospinal tract fibers enter into the spinal gray matter. We have noted that cell populations close to the ventral part of the dorsal funiculus express EphA4 (data not shown) and a possible explanation for the shallower dorsal funiculus may be that these cells are positioned closer or over the midline in the ephrin-B3 mutant mice. Potential roles of ephrin-B3 in regulating earlier crossing events, for example, those of the commissural axons at the floor plate where ephrin-B3 is prominently expressed (Gale et al. 1996a), will also be of interest for future study.

The major neurologic abnormalities of the ephrin$\mathrm{B}^{-/-}$mice are remarkably similar to those described for mice lacking the EphA4 receptor (Dottori et al. 1998; Kullander et al. 2001), which is quite interesting because this receptor binds with high affinity to ephrin-B3 as well as to other ephrins (Gale et al. 1996a,b). The more recent characterization of mice lacking EphA4 not only defined anatomical defects involving the corticospinal tract essentially identical to those we report for the ephrin-B3 ${ }^{-/-}$mice (i.e., involving abnormal recrossing of pro- jections within the spinal gray matter), but it also convincingly showed that EphA4 is expressed by the corticospinal axons themselves (Kullander et al. 2001). Our data, taken together with these published findings, lead us to propose the following model: Corticospinal tract axons originating from each side of the motor cortex separately converge ipsilaterally as they pass through the internal capsule, and remain ipsilateral as they proceed to the ventral caudal medulla, where they cross the midline and shift dorsally at the decussation, forming the dorsal funiculus. Though the corticospinal tract axons express EphA4, their guidance to this point appears unchanged in the EphA4 and ephrin-B3 mutant mice and is thus not dependent on these proteins, presumably because the EphA4-expressing axons do not encounter ephrin-B3 barriers to this point; at the decussation, ephrin$\mathrm{B} 3$ is prominently expressed at the midline, but dorsal to the decussating fibers where it presumably does not interfere with their crossing. Within the dorsal funiculus, in which the corticospinal tract axons normally travel only on the side contralateral to their cortical side of origin, ephrin-B3 plays a minor role in preventing recrossing, as evidenced by rare recrossed axons detected within the dorsal funiculus of ephrin-B3 mutant mice. However, once these axons project into the spinal gray matter, the binding of their EphA4 receptors to ephrin$\mathrm{B} 3$ at the midline forms the major barrier that prevents them from recrossing from contralateral to ipsilateral sides, as evidenced by the abundant recrossed projections seen in the EphA4 and ephrin-B3 mutant mice along the entire rostro-caudal extent of the cord. This abnormal recrossing at the midline results in aberrant bilateral cortical input into the cord, thus resulting in loss of unilateral motor control and the characteristic hopping gait noted in both EphA4 and ephrin-B3 mutant mice.

While Dottori et al. (1998) described a similar neurologic phenotype in their mice lacking EphA4, they reached different conclusions concerning the relative distributions of ephrin-B3 and EphA4 as compared to those reported herein and by Kullander et al. (2001) as well as Martone et al. (1997). In particular, Dottori et al. (1998) suggested that ephrin-B3 was expressed by the corticospinal tract axons, whereas EphA4 was made in surrounding regions, raising the possibility of "reverse signaling" via ephrin-B3 on the corticospinal tract axons. This possibility seems to have largely been eliminated by the more recent distribution studies as well as by satisfying evidence that cell autonomous EphA4 kinase activity is necessary for corticospinal tract axon guidance, because a genetically modified mouse carrying a kinase-dead version of EphA4 displays the identical corticospinal tract axon recrossing defect as the EphA4 null mouse (Kullander et al. 2001).

The characterizations of mice lacking EphA4 revealed major neuroanatomical defects in the formation of the anterior commissure (AC), a major forebrain axon tract that consists of an anterior (aAC) and posterior branch (pAC), which connect both lobes of olfactory bulbs and temporal cortex respectively (Dottori et al. 1998; Kullander et al. 2001). Because of the aforementioned simi- 
larities in the corticospinal defects between ephrin-B3 knockout mice and EphA4 knockout mice, we examined the morphology of the anterior commissure in adult ephrin-B3 mutant brains, and found the normal trajectory of $\mathrm{AC}$ axons just below the ventricular zone of the third ventricle and close to the ventral edge of the striatum (Fig. 3A,B; data not shown). These results show that in contrast to EphA4, ephrin-B3 function is not critical for the proper formation of the anterior commissure. Because EphA4 binds to multiple ephrins, it seems likely that it interacts with an ephrin other than ephrin-B3 during its role in the formation of the anterior commissure.

Finally it should be noted that M. Henkemeyer and colleagues have generated their own line of mice lacking ephrin-B3, and describe findings quite analogous to those reported herein (Yokoyama et al. 2001). Thus, our findings, combined with those of Yokoyama et al. (2001) as well as Dottori et al. (1998) and Kullander et al. (2001) establish the importance of the EphA4 receptor in recognizing a midline barrier signal provided by the ephrinB3 ligand. By preventing recrossing of corticospinal tract projections into the spinal gray matter, EphA4 and ephrin-B3 ultimately allow for unilateral motor control. It seems very likely that ephrin ligands and Eph receptors will continue to emerge as critical mediators of axonal guidance during neural development.

\section{Materials and methods}

\section{Targeting vector construction and ES cell manipulations}

The $5^{\prime}$ and $3^{\prime}$ ephrin-B3 gene fragments used in the construction of the targeting vector were isolated from a 129SV mouse genomic library in the lambda Zap vector (Stratagene). The $5^{\prime}$ region of homology incorporated in the targeting construct consisted of a $4.1 \mathrm{~kb}$ NotI/NheI restriction fragment derived from an ephrinB3 genomic clone spanning the first exon (the $5^{\prime}$ NotI site was contributed by the lambda phage from which this fragment was obtained), which terminated at its $3^{\prime}$ end 680 nucleotides upstream of the ephrin-B3 start codon. This fragment was cloned into NotI and NheI sites in the polylinker upstream of a promoterless LacZ cDNA in the vector pKOVpLacZ, which is comprised of the LacZ gene followed by the phosphoglycerate kinase promoter-driven neomycin resistance gene (PGK-Neo), and the HSV-tk gene (Suri et al. 1996). A 3' region of homology consisting of a $2.4 \mathrm{~kb}$ HindIII fragment, which terminates at its $5^{\prime}$ end 52 nucleotides downstream of intron $1 /$ exon1 boundary. This fragment was subcloned into a HindIII site of pKOVpLacZ between the PGK-Neo and HSV-tk expression units (Suri et al. 1996). In this targeting scheme, 854 nucleotides of the ephrin-B3 gene, including the transcriptional start site and signal sequence, were deleted and replaced by the LacZ and Neo genes. Gene targeting in ES cells and mice derived from them were confirmed by Southern blotting using EcoRI digests (Fig. 1).

\section{Northern blotting}

Northern blot analysis from total RNA was performed as previously described (Maisonpierre et al. 1990).

\section{Tracing of the corticospinal tract}

Animals were anesthetized with a ketamine/xylazine mix (100/ $10 \mathrm{mg} / \mathrm{kg}$ body weight; i.p., Ketalar, Parke-Davis) and the motor cortex was pressure injected with the anterograde tracer biotin dextran amine (10\% BDA in 0.1 M PBS; molecular probes; $4 \mu \mathrm{L}$ into eight to ten injection sites). After a survival time of $10 \mathrm{~d}$, the animals received an overdose of ketamine/xylazine and were transcardially perfused with $0.1 \mathrm{M}$ PBS at $\mathrm{pH}$ 7.4, followed by $4 \%$ paraformaldehyde in PBS.

\section{Tissue processing}

Cryosections of traced brain and spinal cord $(50-100 \mu \mathrm{m})$ were collected and incubated overnight with an avidin-biotin-peroxidase complex (Vectastain ABC Elite Kit, 1:100 in PBS + 1\% Tween-20) at room temperature. Sections were reacted with diaminobenzidine (DAB), mounted on slides, dehydrated, cleared in a 1:1 mixture of benzyl alcohol/benzyl benzoate, cover slipped, and examined under darkfield optics using a Zeiss Axiophot microscope. For gray matter stain, spinal cord cryosections $(50-100 \mu \mathrm{m})$ were incubated $24 \mathrm{~h}$ in DAB solution from a DAB-peroxidase staining kit to reveal endogenous peroxidase activity in cell bodies. For detection of the AC in brains of mutant mice, 30-100 $\mu \mathrm{m}$ cryostat floating sections were collected in PBS, mounted on slides, and photographed while wet using a Nikon SMZ-U dissecting microscope equipped with a subilluminating module.

\section{In situ hybridization}

DIG in situ hybridizations on $8 \mu \mathrm{m}$ paraffin sections were performed according to standard protocols. Antisense riboprobes were transcribed in vitro and labeled by incorporation of digoxygenin-linked UTP (Roche) from the linearized ephrin-B3 template, a 1021-bp fragment extending from nucleotide 1-1021 (accession no. NM007911).

\section{General behavioral methods}

Adult male mice ( 2 mo of age, 38-46 g) were evaluated in three behavioral tasks. Body weight was determined during the behavioral testing period. Gait analysis was performed using the footprint test, fine motor coordination was performed using the sticker/tape test, and general coordination and balance were determined using the rotorod. Animals were housed (1-2 per cage) in a standard temperature and pressure-controlled colony room on a 12:12, light:dark cycle (lights on 06:00 h). Food and water were available ad libitum. All behavioral testing occurred between 13:00 and 15:00 $\mathrm{h}$ in a behavioral testing room located within the animal facility. Mice were transferred to the behavioral testing room 45-90 min before behavioral testing to allow them to acclimate to the room. The experimenter evaluating the animals remained blind to genotype throughout the behavioral testing and analysis.

\section{Gait analysis}

Gait analysis was conducted essentially as described for rats (Johnston et al. 1991) using a $120 \mathrm{~cm}$ long, $9 \mathrm{~cm}$ wide, black runway with $30 \mathrm{~cm}$ high walls on both sides and the starting end. White paper was placed along the bottom of the runway. Mice were trained to run down the runway the day before the testing day. Before analysis, the feet of the mice were painted with nontoxic acrylic paint (forepaws red, hindpaws blue).

Footprints were analyzed for base width (the medial/lateral distance between either the hindpaws or the forepaws), stride length (the distance from one paw being set down until it is set down again), and interstep distance (the distance from one hindpaw or forepaw until the hindpaw or forepaw on the opposite side). Measurements were taken from three consecutive steps 
with a continuous gait. The median of the three measurements for each parameter was counted as the measurement for final analysis. Each gait parameter was analyzed using an independent groups Student's $t$ test, with alpha set at 0.05 .

\section{Sticker/tape test}

A small sticker was placed on the snout of each mouse in its home cage within the behavioral testing room, and the latency to remove the sticker was recorded. Each animal received three trials, and the median trial was counted in the final analysis. Sticker Test results were analyzed with an independent groups Student's $t$ test, with alpha set at 0.05 .

\section{Rotorod testing}

Animals were pretrained on a rotorod apparatus (Columbus Instruments, rods $7 \mathrm{~cm}$ in diameter) for $2 \mathrm{~d}$ before the testing day. On the first day, animals spent 1 min exploring the apparatus, and then spent 2 min walking on the rotorod at low speed $(\sim 2$ rpm). On the second day of training, animals spent $30 \mathrm{sec}$ exploring the apparatus, and then spent 2 min walking on the rotorod at increasing speeds (up to $7 \mathrm{rpm}$ ). Any animal that fell off the rotorod during training was replaced on the rotorod apparatus. On the day of testing, animals were placed on the rotorod for $150 \mathrm{sec}$, with $30 \mathrm{sec}$ each at 2, 3, 4, 5, and $6 \mathrm{rpm}$. The $2 \mathrm{rpm}$ speed served as $30 \mathrm{sec}$ of acclimation to the rotorod. Timing was started when the speed was turned up to $3 \mathrm{rpm}$, and continued for $120 \mathrm{sec}$ or until the animal either fell off or rotated upside down on the apparatus. Animals that remained on the rotorod for the entire trial received a score of 120, and all others received a score corresponding to their latency to fall. Latencies for the single trial were analyzed using a Student's $t$ test, with alpha set at 0.05 .

\section{Growth cone collapse assay}

Cortical neurons were dissected from the anterior dorsomedial to dorsal neocortex of E16.5 mouse embryos. Cells were dissociated with papain and plated in neurobasal medium with B27 supplement (GIBCO BRL) on glass coverslips pretreated with nitric acid and coated with poly-D-lysine and laminin. Low density cultures ( 10-20 K neurons/coverslip) required the addition of $1 / 3$ conditioned medium obtained from high-density 4-dayold cortical cultures. After $2 \mathrm{~d}$ in culture, cells were treated with preclustered $(1 / 10 \mathrm{w} / \mathrm{w} \alpha \mathrm{hFc} / \mathrm{hFc}, 1 \mathrm{~h}$ at room temperature) ephrin-B3-hFc or hFc at a concentration of $1 \mu \mathrm{g} / \mathrm{mL}$ in fresh culture medium for $30 \mathrm{~min}$. The cells were fixed with $4 \%$ PFA and stained with TRITC-phalloidin. Scoring of growth cones as collapsed or uncollapsed were performed blinded and were counted from cells with at least two neurites, with one neurite at least twice as long as the others. Only the growth cone of the longest neurite was counted. "Axon" tips with filopodial extensions and dense phalloidin staining were considered as uncollapsed growth cones. Pointed "axon" tips without filopodial extensions and no dense phalloidin staining were considered as collapsed growth cones.

\section{Acknowledgments}

We thank members of the Regeneron and EMBL communities for their support. In particular we thank Stan Weigand for help with axon tracing experiments and interpretation of brain anatomy; Anthony Lucarelli and Bill Poueymirou for assistance with blastocyst injections; Annika Porthin for help with in situ hybridizations; Mary Simmons and Louise Freed for assistance with animal husbandry and dissections; Lakeisha Esau for assistance with genotyping. We gratefully acknowledge Marc Tessier-Lavigne and Philip A. Leighton for access to unpublished material. Support for this study came in part from the Deutsche Forschungsgemeinschaft, from Human Frontiers Science Program Organization (to R.K.) and TMR grants to R.K. and K.K., respectively. K.K. is a Marie Curie Fellow.

The publication costs of this article were defrayed in part by payment of page charges. This article must therefore be hereby marked "advertisement" in accordance with 18 USC section 1734 solely to indicate this fact.

\section{References}

Brose, K., Bland, K.S., Wang, K.H., Arnott, D., Henzel, W., Goodman, C.S., Tessier-Lavigne, M., and Kidd, T. 1999. Slit proteins bind robo receptors and have an evolutionarily conserved role in repulsive axon guidance. Cell 96: 795-806.

Davis, S., Gale, N.W., Aldrich, T.H., Maisonpierre, P.C., Lhotak, V., Pawson, T., Goldfarb, M., and Yancopoulos, G.D. 1994. Ligands for EPH-related receptor tyrosine kinases that require membrane attachment or clustering for activity. Science 266: 816-819.

Dottori, M., Hartley, L., Galea, M., Paxinos, G., Polizzotto, M., Kilpatrick, T., Bartlett, P.F., Murphy, M., Kontgen, F., and Boyd, A.W. 1998. EphA4 (Sek1) receptor tyrosine kinase is required for the development of the corticospinal tract. Proc. Natl. Acad. Sci. 95: 13248-13253.

Erskine, L., Williams, S.E., Brose, K., Kidd, T., Rachel, R.A., Goodman, C.S., Tessier-Lavigne, M., and Mason, C.A. 2000. Retinal ganglion cell axon guidance in the mouse optic chiasm: Expression and function of robos and slits. J. Neurosci. 20: 4975-4982.

Flanagan, J.G. and Vanderhaeghen, P. 1998. The ephrins and Eph receptors in neural development. Annu. Rev. Neurosci. 21: 309-345.

Gale, N.W. and Yancopoulos, G.D. 1997. Ephrins and their receptors: A repulsive topic? Cell Tissue Res. 290: 227-241.

Gale, N.W., Flenniken, A., Compton, D.C., Jenkins, N., Copeland, N.G., Gilbert, D.J., Davis, S., Wilkinson, D.G., and Yancopoulos, G.D. 1996a. Elk-L3, a novel transmembrane ligand for the Eph family of receptor tyrosine kinases, expressed in embryonic floor plate, roof plate and hindbrain segments. Oncogene 13: 1343-1352.

Gale, N.W., Holland, S.J., Valenzuela, D.M., Flenniken, A., Pan, L., Ryan, T.E., Henkemeyer, M., Strebhardt, K., Hirai, H., Wilkinson, D.G., Pawson, T., et al. 1996b. Eph receptors and ligands comprise two major specificity subclasses and are reciprocally compartmentalized during embryogenesis. Neuron 17: 9-19.

Guastavino, J.M., C. Sotelo, et al. 1990. Hot-foot murine mutation: Behavioral effects and neuroanatomical alterations. Brain Res. 523: 199-210.

Imondi, R., Wideman, C., and Kaprielian, Z. 2000. Complementary expression of transmembrane ephrins and their receptors in the mouse spinal cord: A possible role in constraining the orientation of longitudinally projecting axons. Development 127: 1397-1410.

Johnston, R.B. Zachary, L., Dellon A.L., Seiler, W.A., and Teplica, D.M. 1991. Improved imaging of rat hindfoot prints for walking track analysis. J. Neurosci. Methods 38: 111-114.

Joosten, E.A. and Bar, D.P. 1999. Axon guidance of outgrowing corticospinal fibres in the rat. J. Anat. 194: 15-32.

Kidd, T., Brose, K., Mitchell, K.J., Fetter, R.D., Tessier-Lavigne, 
M., Goodman, C.S., and Tear, G. 1998. Roundabout controls axon crossing of the CNS midline and defines a novel subfamily of evolutionarily conserved guidance receptors. Cell 92: 205-215.

Kullander, K., Mathers, N., Diella, F., Dottori, M., Boyd, A.W., and Klein, R. 2001. Kinase-dependent and kinase-independent functions of EphA4 receptors in major axon tract formation in vivo. Neuron 29: 73-84.

Leighton, P.A., Mitchell, K.J., Goodrich, L., Lu, X., Pinson, K., Wakenight, P., Tate, P., Skarnes, W.C., and Tessier-Lavigne, M. 2001. A large scale gene trap screen for brain wiring molecules in mice. Nature 410: 174-179.

Maisonpierre, P.C., Belluscio, L., Squinto, S., Ip, N.Y., Furth, M.E., Lindsay, R.M., and Yancopoulos, G.D. 1990. Neurotrophin-3: A neurotrophic factor related to NGF and BDNF. Science 247: 1446-1451.

Marcus, R.C., Matthews, G.A., Gale, N.W., Yancopoulos, G.D., and Mason, C.A. 2000. Axon guidance in the mouse optic chiasm: Retinal neurite inhibition by ephrin " $\mathrm{A}$ "-expressing hypothalamic cells in vitro. Dev. Biol. 221(1): 132-147.

Martone, M.E., Holash, J.A., Bayardo, A., Pasquale, E.B., and Ellisman, M.H. 1997. Immunolocalization of the receptor tyrosine kinase EphA4 in the adult rat central nervous system. Brain Res. 771: 238-250.

Nakagawa, S., Brennan, C., Johnson, K.G., Shewan, D., Harris, W.A., and Holt, C.E. 2000. Ephrin-B regulates the ipsilateral routing of retinal axons at the optic chiasm. Neuron 25: 599610.

Paxinos, G. 1985. Hindbrain and spinal cord. In The Rat Nervous System (ed. George Paxinos), pp. 311-324. Academic Press, San Diego.

Piper, M., Georgas, K., Yamada, T., and Little, M. 2000. Expression of the vertebrate slit gene family and their putative receptors, the robo genes, in the developing murine kidney. Mech. Dev. 94: 213-217.

Suri, C., Jones, P.F., Patan, S., Bartunkova, S., Maisonpierre, P.C., Davis, S., Sato, T.N., and Yancopoulos, G.D. 1996. Requisite role of angiopoietin-1, a ligand for the TIE2 receptor, during embryonic angiogenesis. Cell 87: 1171-1180.

Tessier-Lavigne, M. and Goodman, C.S. 1996. The molecular biology of axon guidance. Science 274: 1123-1133.

Yokoyama, N., Romero, M.I., Cowan, C.A., Galvan, P., Helmbacher, F., Charnay, P., Parada, L.F., and Henkemeyer, M. 2001. Forward signaling mediated by ephrin-B3 prevents contralateral corticospinal axons from recrossing the spinal cord midline. Neuron 29: 85-97. 


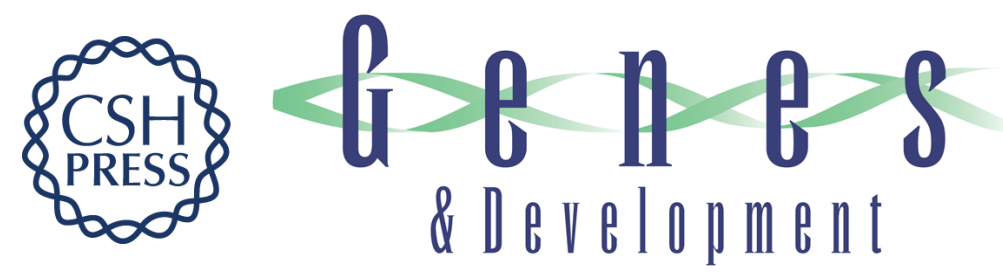

\section{Ephrin-B3 is the midline barrier that prevents corticospinal tract axons from recrossing, allowing for unilateral motor control}

Klas Kullander, Susan D. Croll, Manuel Zimmer, et al.

Genes Dev. 2001, 15:

Access the most recent version at doi:10.1101/gad.868901

References This article cites 22 articles, 6 of which can be accessed free at: http://genesdev.cshlp.org/content/15/7/877.full.htmI\#ref-list-1

License

Email Alerting

Receive free email alerts when new articles cite this article - sign up in the box at the top Service right corner of the article or click here.

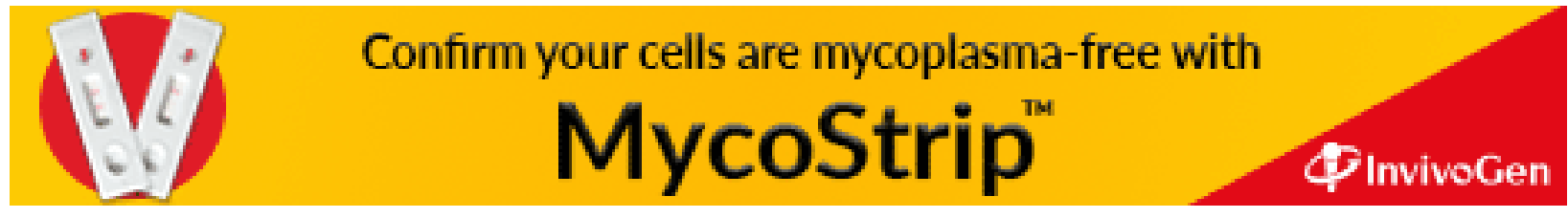

